\title{
Metal-Atom Impact on the Self-Assembly of Cup-and-Ball Metalloporphyrin-Fullerene Conjugates
}

\author{
Luis Moreira, ${ }^{[a],[b]}$ Joaquín Calbo, ${ }^{[c]}$ Beatriz M. Illescas, ${ }^{[b]}$ Juan Aragó, ${ }^{[c]}$ Iwona Nierengarten, ${ }^{[a]}$ Béatrice \\ Delavaux-Nicot, ${ }^{[d]}$ Enrique Ortí, ${ }^{*[c]}$ Nazario Martín ${ }^{*[b]}$ and Jean-François Nierengarten. ${ }^{*[a]}$
}

This work is dedicated to Professor Jean-Pierre Sauvage on the occasion of his $70^{\text {th }}$ birthday.

\begin{abstract}
A fullerene-ammonium derivative has been combined with different metalloporphyrin-crown ether receptors to generate very stable supermolecules. The combination of fullerene-porphyrin and ammonium-crown ether interactions leads to a strong chelate effect as evidenced by a high effective molarity $(3.16 \mathrm{M})$. The different parameters influencing the stability of the supramolecular ensembles, in particular the nature of the metal in the porphyrin moiety, have been rationalized with the help of theoretical calculations thus providing new insights into fullerene-porphyrin interactions.
\end{abstract}

Construction of artificial photoactive devices capable of mimicking photosynthesis by transforming sunlight into chemical potential is one of the most sought objectives in the quest for new sources of energy. ${ }^{[1]}$ For this purpose, chemists have developed a wide variety of donor-acceptor systems where photon energy is used to produce a photoinduced electron transfer from the donor to the acceptor moiety. ${ }^{[2]}$ Among them, porphyrins and fullerenes have extensively been combined due to their respective notable electron-donor and electron-acceptor properties. ${ }^{[3]}$

Most of the research on porphyrin-fullerene conjugates has been based on covalent chemistry. ${ }^{[4]}$ However, considering the versatility of non-covalent interactions, a variety of supramolecular ensembles involving both chromophores has

[a] Dr. L. Moreira, Dr. I. Nierengarten, Prof. Dr. J.-F. Nierengarten Laboratoire de Chimie des Matériaux Moléculaires Université de Strasbourg et CNRS (UMR 7509) ECPM, 25 rue Becquerel, 67087 Strasbourg (France) E-mail: nierengarten@unistra.fr

[b] Dr. L. Moreira, Dr. B. M. Illescas, Prof. Dr. N. Martín Departamento de Química Orgánica, Fac. C.C. Químicas Universidad Complutense de Madrid

Av. Complutense s/n, 28040 Madrid (Spain)

E-mail: nazmar@ucm.es

[c] J. Calbo, Dr. J. Aragó, Prof. Dr. E. Ortí Instituto de Ciencia Molecular, Universidad de Valencia Catedrático José Beltrán 2, 46980 Paterna (Spain)

E-mail: enrique.orti@uv.es

[d] Dr. B. Delavaux-Nicot

Laboratoire de Chimie de Coordination du CNRS (UPR 2841)

Université de Toulouse (UPS, INPT)

205 route de Narbonne, 31077 Toulouse Cedex 4 (France)

$\left[{ }^{* *}\right]$ This work was supported by the European Research Council (ERC2012-ADG_20120216 (Chirallcarbon), Ministerio de Economía y Competitividad (MINECO) of Spain (projects CTQ2011-24652 and CTQ2012-31914), the Comunidad Autónoma de Madrid (MADRISOLAR-2 project S2009/PPQ-1533), the Generalitat Valenciana (PROMETEO/2012/053) and European FEDER funds (CTQ2012-31914). L. M. thanks the Obra Social "la Caixa" for a postgraduate fellowship. J. C. acknowledges the Spanish Ministry of Education, Culture and Sport (MECD) for an FPU grant.

Supporting information for this article is given via a link at the end of the document. been reported. ${ }^{[5]}$ Surprisingly, while many of these examples involve $\pi-\pi$ interactions between both components, the nature of this affinity, which challenges the traditional belief that a curved guest requires curved hosts for effective complexation, ${ }^{[6]}$ is not yet fully understood. Crystallographic data suggests that it stems from the attraction between the higher electron density of a $[6,6]$ double bond of the fullerene sphere and the protic center of a freebase porphyrin or the metal of a metalloporphyrin, therefore confronting the general notion of fullerenes as molecular acceptors. ${ }^{[7]}$ In addition, little is known on the role of the metal atom. ${ }^{[8]}$ To the best of our knowledge, there are few examples dealing with this issue in solution: the porphyrin sandwiches developed by $\mathrm{Aida}^{[9]}$ and the "jaws porphyrins"[10] and the calix[4]arene-linked bisporphyrins ${ }^{[11]}$ developed by Reed and Boyd. None of these papers manage to fully rationalize the binding or association constants $\left(K_{\mathrm{a}}\right)$ for the different metals beyond pointing to the existence of an electrostatic component as free-base porphyrins bind fullerenes with a similar strength than their $\mathrm{Zn}(\mathrm{II})$ analogous. ${ }^{[8 \mathrm{a}]}$ One of them even suggests that the high binding constants obtained in the complexation of fullerenes can be ascribed to their desolvation rather than to electronic effects. ${ }^{[11]}$ Computational studies mainly point to the presence of dispersion forces in the complex and do not provide an accurate analysis of the interaction. ${ }^{[8 a}$, 12]

Furthermore, supramolecular complexes presenting a single porphyrin-fullerene $\pi-\pi$ interaction are readily dissociated in solution, given their low thermodynamic stability, making their study more challenging. However, inclusion of additional supramolecular recognition motifs can lead to a cooperative stabilization of the complex as previously reported in our group, where the introduction of an additional ammonium-crown-ether interaction dramatically stabilized the resulting complex. ${ }^{[13]}$ Therefore, understanding and quantifying the cooperative interplay between different non-covalent interactions and the structure of the supramolecular complexes obtained remain a major challenge. ${ }^{[14]}$ For this, the effective molarity (EM) is a key parameter, as it assesses the chelate effect of a system by accounting for the easier formation of an intramolecular reaction over its intermolecular analogous (Scheme 1). ${ }^{[15]}$

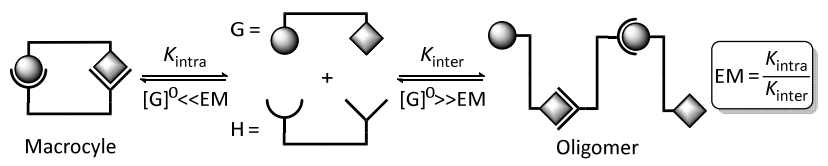

Scheme 1. EM quantifies the ease of cyclization vs. oligomerization

In order to shed new light on these topics, this paper presents a complete study on the effect of different metals, namely $\mathrm{Co}, \mathrm{Ni}$, $\mathrm{Cu}$, and $\mathrm{Zn}$ on the binding constant of a series of novel 
metalloporphyrin-[60]fullerene cup-and-ball complexes. Their self-assembly is assessed through the EM of the Zn-based complex and their $K_{a}$ values are rationalized with the help of electrochemical studies and quantum-chemistry calculations.

Targeted complexes [1-M•3] were obtained by mixing the corresponding porphyrin-crown-ether conjugates $(\mathbf{1}-\mathbf{M} ; \mathrm{M}=2 \mathrm{H}$, $\mathrm{Co}, \mathrm{Ni}, \mathrm{Cu}, \mathrm{Zn}$ ) and the methano[60]fullerene derivative $\mathbf{3}^{[16]}$ as shown in Scheme 2.

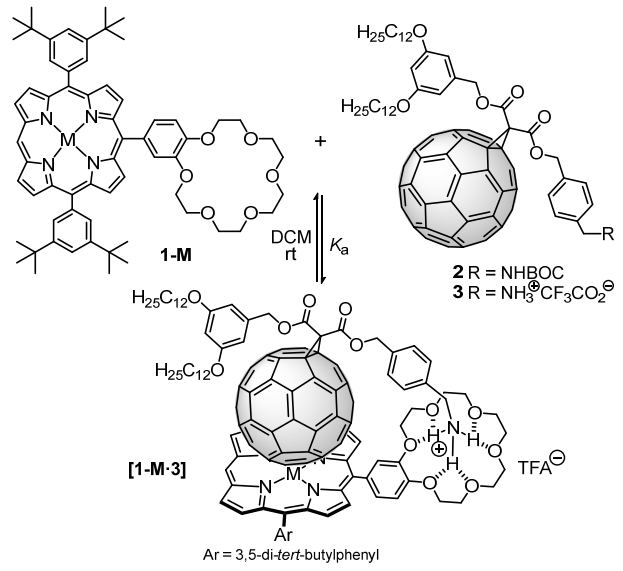

Scheme 2. Formation of supramolecular complexes [1-M•3] from their corresponding building blocks $1-\mathbf{M}(\mathrm{M}=2 \mathrm{H}, \mathrm{Co}, \mathrm{Ni}, \mathrm{Cu}, \mathrm{Zn})$ and $\mathbf{3}$.

Complexation was first evidenced by ${ }^{1} \mathrm{H}-\mathrm{NMR}$. Addition of 1 eq of $\mathbf{3}$ to $\mathbf{1 - Z n}$ resulted in a fast equilibrium leading to a shift of the signals particularly visible in the aromatic region (see Figure S1 in the Supporting Information).

Measurement of the binding constant of [1-M-3] was undertaken by monitoring the changes in the UV-vis absorption spectra of $\mathbf{1 - M}$ after addition of increasing quantities of $\mathbf{3}$ in DCM at $\mathrm{rt}$. A representative example is the formation of [1-Zn•3] (Figure S3). Addition of increasing quantities of 3 to $1-Z n$ resulted in a red shift of the Soret band $\left(\lambda_{\max }=416 \mathrm{~nm} \rightarrow 423 \mathrm{~nm}\right)$, which was observed in all the complexes (see Figure S4). This shift has been accounted for by the charge transfer from the axial ligand to the porphyrin ring, ${ }^{[17]}$ and is widely used as an evidence of the presence of intermolecular $\pi$-stacking. ${ }^{[5 \mathrm{~d}]}$

The appearance of a single isosbestic point at $422 \mathrm{~nm}$ suggests a single equilibrium between the unbounded and the bounded species. ${ }^{[18]}$ Given the unlikely formation of a 1:2 complex by simultaneous collision of three molecules, this is most probably a 1:1 complex. This stoichiometry is in line with that found for a related system developed by our group ${ }^{[13]}$ and was also evidenced by positive ESI-MS. Thus, the mass spectrum obtained from an equimolar mixture of $\mathbf{1 - Z n}$ and $\mathbf{3}$ in DCM displayed a single-charged ion peak at $\mathrm{m} / \mathrm{z} 2461.00$ ascribable to the $1: 1$ complex [1-Zn•3] after loss of the counteranion (calculated $\mathrm{m} / \mathrm{z}$ 2461.00). In addition, the MS of a 1:4 mixture of $1-Z n: 3$ showed exclusively the peak corresponding to a 1:1 stoichiometry (see Figure S2). Finally, non-linear curve fitting of the titration data using Specift multivariate analysis software (see Supporting Information) fitted to a 1:1 model and led to the $K_{\mathrm{a}}$ values reported in Table 1.

Interestingly, the pattern found for the binding constants of [1-M•3] complexes is very different from those reported in previous studies as [1-2H•3] does not bind fullerene with a similar strength than [1-Zn・3]. ${ }^{[9-11]}$ Indeed, the values obtained in our series correlate with that expected for a porphyrin $\cdot \mathrm{C}_{60}$ associate governed by van der Waals forces, where $K_{\mathrm{a}}$ becomes larger as the number of electrons in the porphyrin increases, with the sole exception of [1-Co・3]. Its different behavior can be accounted for on the basis of the strong interaction between fullerenes and group 9 metals (Co, Rh, Ir), ${ }^{[9 a]}$ which has been related to the partial occupation of the Co- $\mathrm{d}_{\mathrm{z}}{ }^{2}$ orbital, leading to less repulsive interactions. ${ }^{[12 b]}$ Experimentally this is evidenced by the fact that the Soret band of 1-Co experiments the largest red shift of all the series $\left(\Delta \lambda_{\max }=24 \mathrm{~nm}\right)$, suggesting a larger charge transfer interaction (see the Supporting Information).

Table 1. Calculated binding constants $\left(K_{\mathrm{a}}\right)$ for porphyrins $1-\mathbf{M}$ towards the methanofullerene derivative 3 at $25^{\circ} \mathrm{C}$ in DCM.

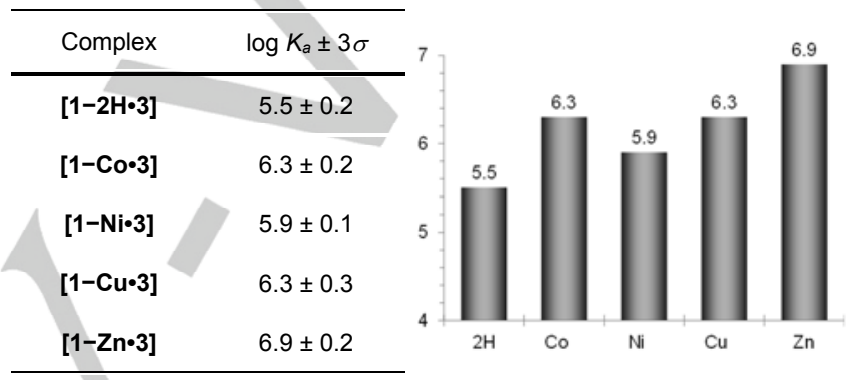

It is crucial to note that all previous examples consisted on the complexation of pristine $\mathrm{C}_{60}$, whose low solubility limited the choice of solvents for the titration experiment making its desolvation the driving force of the complexation, as already mentioned in the introduction. ${ }^{[11]}$ The use of methanofullerene 3 has elegantly circumvented this limitation, enabling us to have a better insight into the nature of this interaction, while basically retaining the original properties of the fullerene moiety.

The chelate effect in these self-assembled systems was assessed by estimating the EM of the reference complex $[1-Z n \cdot 3]$. For this, each of the interactions leading to the complex was independently evaluated and compared to the overall stability, $K_{\mathrm{a}}$ (Scheme 3). ${ }^{[19]}$ The porphyrin conjugate $\mathbf{1 - Z n}$ was combined with methanofullerene $\mathbf{2}$, whose ammonium moiety is protected preventing any $\mathrm{H}$-bonding interaction, to evaluate the porphyrinfullerene interaction. The strength of the ammonium-crown-ether motif was evaluated by titrating 3 with $6 .{ }^{[20]}$ The high EM obtained $(3.16 \mathrm{M})$ reflects how introducing the ammonium-crown-ether association as an additional recognition motif increases the complementarity of the building blocks with a minimum cost in their preorganization.

The supramolecular complexes were further studied by Osteryoung Square Wave Voltammetry (OSWV) and Cyclic Voltammetry $(\mathrm{CV})$. Formation of [1-M・3] led to changes of the electrochemical signature of the [1-M] porphyrins suggesting donor-acceptor interactions in the ground state (see Table S1 and Figures S8-S10). Indeed, a slight shift of the first oxidation potential and a change in intensity are detected by OSWV upon interaction. In the case of [1-Co], the first oxidation potential is centered on the metal and not on the $\pi$-system of the porphyrin ligand. ${ }^{[21]}$ In CV, for this particular association, an apparent anodic 
shift of the first oxidation potential $(\Delta E=220 \mathrm{mV})$ is observed (see Figure S10). This is the most important shift value in comparison with all the other cases and is in line with specific interactions of the metal center and the fullerene sphere (vide supra). As for the reduction, a significant anodic shift (ca. $50 \mathrm{mV}$ ) of the first reduction of the fullerene moiety upon addition of 3 to [1-Co] further evidences this phenomenon.

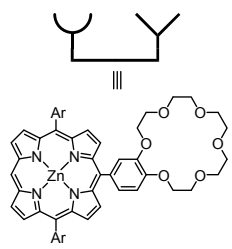

$1-\mathrm{Zn}$

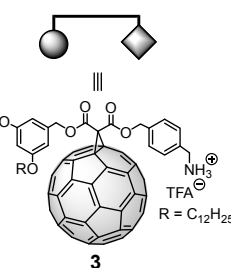

3

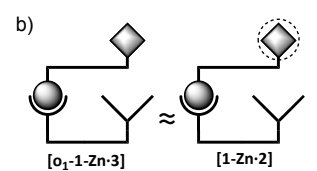

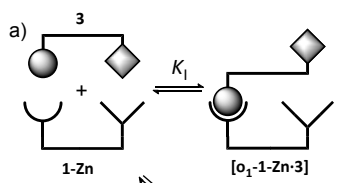

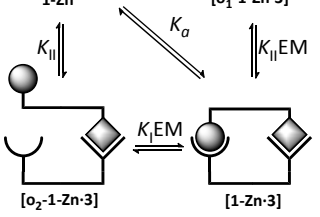

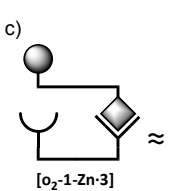

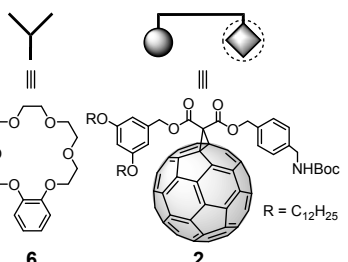

$\log K_{\mathrm{a}}=5.1 \pm 0.1$ $\log K_{1}=1.3 \pm 0.3$ $\log K_{\|}=3.3 \pm 0.1$

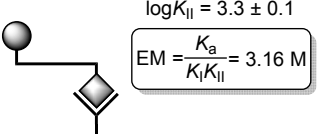

[6.3]

Scheme 3. a) The EM is obtained by evaluating each supramolecular interaction separately. b) The porphyrin-fullerene interaction was assessed by ${ }^{1} \mathrm{H}$-NMR titration of $\mathbf{1 - Z n}$ with methanofullerene $\mathbf{2}$ in $\mathrm{CDCl}_{3}$ at $\mathrm{rt}$ yielding $\mathrm{K}_{\mathrm{l}}$ (Figures S5 and S6). c) The stability of the ammonium-crown-ether association, $K_{\text {III }}$ was evaluated by ${ }^{1} \mathrm{H}-\mathrm{NMR}$ titration of 3 with crown ether $6 .{ }^{[20]}$ The overall binding constant, $K_{\mathrm{a}}$, was obtained by UV-vis titration of $1-\mathrm{Zn}$ with 3 in $\mathrm{CHCl}_{3}$ at rt (see Figure S7).

The molecular structures and binding energies of the [1-M•3] complexes were theoretically investigated in order to gain a better understanding of the different interactions governing the associates (see the Supporting Information for full computational details). Geometry optimizations were first performed at the semiempirical PM7 level and show that, after full-geometry relaxation, the ammonium group of the methanofullerene interacts with the crown ether of the porphyrin by $\mathrm{H}$-bond formation, whereas the fullerene ball recognizes the center of the porphyrin system by non-covalent forces (Figure 1).

Accurate density functional theory (DFT) optimizations of the [1-M•3] geometries were performed at the B97-D/6-31G* level starting from the PM7-optimized structures (see Figure S11 for the DFT-optimized geometries). The main interactions governing the supramolecular association are represented by the $\mathrm{M}-\mathrm{C}_{60}(\mathbf{a})$ and $\mathrm{NH} \cdots \mathrm{O}$ (b) distances given in Table 2 (see Figure 1 for labeling). In addition, $\mathrm{C}-\mathrm{H} \cdots \pi$ dispersion interactions (c and $\mathbf{d}$ ) between the tert-butyl-substituted benzene rings of the porphyrin and the $\pi$-cloud of the fullerene also contribute to the supramolecular complex. The increase in the electron density on the metal atom determines a shortening in the $\mathrm{M}-\mathrm{C}_{60}$ distance from $2.79 \AA$ in [1-Ni-3] to $2.70 \AA$ in [1-Zn•3], and the nonmetallated [1-2H•3] associate presents an intermediate value of $2.76 \AA$ identical to [1-Cu•3]. Calculations predict an $\mathrm{M}-\mathrm{C}_{60}$ distance of only $2.12 \AA$ for [1-Co.3] underestimating the value of 2.60-2.80 $\AA$ recorded for neutral $\mathrm{Co}$ (II) metalloporphyrin complexes. ${ }^{[22]}$ However, as discussed below, this underestimation is presumably due to the relatively small basis set employed in the geometry optimization. The hydrogen bond $\mathrm{NH}^{\cdots} \mathrm{O}$ distances (b) that account for the ammonium-crown-ether interaction do not vary along the series of porphyrin-fullerene associates (Table 2). The $\mathrm{CH}^{\cdots} \mathrm{C}_{60}$ interactions $\mathbf{c}$ and $\mathbf{d}$ are all around $2.60 \AA$ and determine a slight folding of the porphyrin macrocycle to better wrap the fullerene surface.
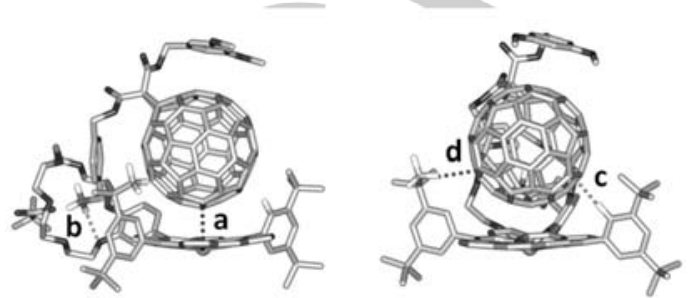

Figure 1. Minimum-energy structure calculated for the [1-Cu•3] complex at the PM7 level. Side (left) and front (right) views are displayed. The different types of intermolecular non-covalent interactions are denoted with labels a-d. Only relevant hydrogen atoms are displayed for clarity.

The association or binding energy $\left(E_{\text {bind }}\right)$ of the [1-M・3] associates was calculated at the PBE0-D3/cc-pVTZ level of theory using the B97-D/6-31G*-optimized geometries (Table 2). Passing from Ni to $\mathrm{Zn}, E_{\text {bind }}$ rises from -88.7 to $-92.8 \mathrm{kcal} / \mathrm{mol}$ due to the more stabilizing $\mathrm{M}-\mathrm{C}_{60}$ interaction that takes place in moving to electron-richer metal atoms. The stabilization in the formation of the non-metallated [1-2H・3] complex amounts to $92.4 \mathrm{kcal} / \mathrm{mol}$, and the largest association energy is computed for [1-Co.3] $(-93.8 \mathrm{kcal} / \mathrm{mol})$. The differences found between the calculated $E_{\text {bind }}$ and the experimental trends found for $K_{\mathrm{a}}$ may arise from the solvent and enthropic effects, which are not taken into account in the calculations.

Table 2. DFT-optimized (B97-D/6-31G*) intermolecular distances (a-d, in $\AA$ ) characterizing the $[1-\mathbf{M} \cdot 3]$ associates, and binding energies $\left(E_{\text {bind }}\right)$ computed at the PBE0-D3/cc-pVTZ level.

\begin{tabular}{cccccc}
\hline Complex & $\begin{array}{c}\mathrm{M}-\mathrm{C}_{60} \\
(\mathbf{a})^{[\mathrm{a}]}\end{array}$ & $\begin{array}{c}\mathrm{NH} \cdots \mathrm{O} \\
(\mathbf{b})^{[\mathrm{b}]}\end{array}$ & $\begin{array}{c}\mathrm{CH} \cdots \mathrm{C}_{60} \\
(\mathbf{c})^{[\mathrm{c}]}\end{array}$ & $\begin{array}{c}\mathrm{CH} \cdots \mathrm{C}_{60} \\
(\mathbf{d})^{[\mathrm{d}]}\end{array}$ & $\begin{array}{c}E_{\text {bind }} \\
(\mathrm{kcal} / \mathrm{mol})\end{array}$ \\
\hline$[1-2 \mathrm{H} \cdot 3]$ & 2.756 & 1.848 & 2.679 & 2.577 & -92.4 \\
{$[1-\mathrm{Co} \cdot 3]$} & 2.119 & 1.850 & 2.642 & 2.573 & -93.8 \\
{$[1-\mathrm{Ni} \cdot 3]$} & 2.793 & 1.842 & 2.623 & 2.610 & -88.7 \\
{$[1-\mathrm{Cu} \cdot 3]$} & 2.754 & 1.846 & 2.662 & 2.599 & -91.3 \\
{$[1-Z n \cdot 3]$} & 2.701 & 1.845 & 2.698 & 2.591 & -92.8 \\
\hline
\end{tabular}

[a] Distance between the center of the porphyrin (the metal atom) and the center of the closest $[6,6]$ bond of $\mathrm{C}_{60}$. [b] Shortest distance between the hydrogen atoms of the ammonium group and the oxygen atoms of the crown ether. [c] Shortest distance between the hydrogen atoms of the peripheral benzene rings of the porphyrin and the closest $\mathrm{C}_{60}$ carbon atom. [d] Shortest distance between the hydrogen atoms of the tert-butyl groups and the closest $\mathrm{C}_{60}$ carbon atom.

In order to quantify the contribution of the main interactions governing the formation of the [1-M・3] complexes, binding energies at the PBE0-D3/cc-pVTZ//B97-D/6-31G* level were computed for simplified model systems of [1-Zn•3] (see Figure 
S12 and Table S2). The non-covalent interaction between the fullerene ball and the phenyl-substituted porphyrin amounts to $22.5 \mathrm{kcal} / \mathrm{mol}$, and the presence of the tert-butyl groups on the meta position of the phenyl rings (interaction d) produces an additional stabilization of approximately $4 \mathrm{kcal} / \mathrm{mol} \quad(-26.3$ $\mathrm{kcal} / \mathrm{mol})$ in agreement with previous theoretical studies. ${ }^{[12 a, 23]}$ The ammonium-crown-ether $\mathrm{NH} \cdots \mathrm{O}$ contacts are computed to be the main stabilizing interaction and provide an interaction energy of $-64.9 \mathrm{kcal} / \mathrm{mol}$, which is three times the stabilization of the porphyrin- $\mathrm{C}_{60}$ interaction in good accord with the experimental trends discussed above (Scheme 3 ). The binding energy obtained from the sum of these three supramolecular interactions $(-91.2$ $\mathrm{kcal} / \mathrm{mol}$ ) is pretty close to the total association energy computed for [1-Zn•3] $(-92.8 \mathrm{kcal} / \mathrm{mol})$ supporting the validity of the analysis performed.

Calculations evidence the charge transfer from the axial $\mathrm{C}_{60}$ ligand to the metal center since the positive charge of the metal decreases in passing from $\mathbf{1 - M}$ to [1-M•3] (see Table S3). This effect is especially important for [1-Co.3] $(0.20 \mathrm{e})$ due to the participation of the Co- $\mathrm{d}_{\mathrm{z}}{ }^{2}$ orbital in the half-filled HOMO (see Figure S15), and determines the larger red shift observed for this complex in the UV-vis spectrum (vide supra). The fullerene guest is therefore acting as a donor giving electronic density to the metal and, at the same time, it is also acting as an acceptor receiving electron density from the porphyrin macrocycle through the $\pi-\pi$ interaction existing between both fragments (see Table S3).

Keeping in mind that $\mathrm{C}_{60}$ interacts with the porphyrin moiety mainly through the electron-rich $[6,6]$ double bonds, ${ }^{[8 a]}$ we modeled a simplified system $\left(\mathbf{M P} \cdot \mathbf{C}_{2} \mathbf{H}_{4}\right)$ in which the pristine porphyrin (MP) interacts with a molecule of ethylene (Figure S13). This reduced model allows performing more accurate calculations to better understand the relative stabilization of the different associates when varying the metal in the porphyrin.

Geometry relaxation of the porphyrin-ethylene complex at the PBE0-D3/cc-pVTZ level led to a minimum-energy conformation in which the ethylene stands parallel to the porphyrin plane with a $C_{2 v}$ molecular symmetry (Figure S13). A clear correlation between the calculated binding energies and metal-ethylene distances is now obtained since the shorter is the distance along the series $\mathbf{N i P} \cdot \mathbf{C}_{2} \mathrm{H}_{4}(3.18 \AA)>\mathrm{CuP} \cdot \mathrm{C}_{2} \mathrm{H}_{4}(3.00 \AA)>\mathrm{ZnP} \cdot \mathbf{C}_{2} \mathrm{H}_{4}(2.75 \AA)>$ CoP. $\mathrm{C}_{2} \mathrm{H}_{4}(2.62 \AA)$, the larger is the stabilization of the complex (Table 3). In comparing the $\mathbf{2} \mathbf{H P} \cdot \mathbf{C}_{2} \mathrm{H}_{4}$ and $\mathbf{C u P} \cdot \mathrm{C}_{2} \mathrm{H}_{4}$ complexes, which have similar $\mathrm{M}$-ethylene distances, the larger association energy computed for the latter suggests that the presence of the metal favors the stabilization of the complex in approximately 1.5 $\mathrm{kcal} / \mathrm{mol}$. The $\mathbf{M}-\mathrm{C}_{2} \mathrm{H}_{4}$ distance computed for the $\mathrm{CoP} \cdot \mathrm{C}_{2} \mathrm{H}_{4}$ associate $(2.62 \AA)$ is significantly longer than that obtained for the [1-Co.3] complex at the B97-D/6-31G* level, and is in good accord with previously reported $\mathrm{M}-\mathrm{C}_{60}$ distances for Co-based porphyrin-fullerene associates. ${ }^{[22]}$

The net charge calculated for the metal atom increases in going from CoP• $\mathrm{C}_{2} \mathrm{H}_{4}(+0.720 \mathrm{e})$ to $\mathrm{ZnP} \cdot \mathrm{C}_{2} \mathrm{H}_{4}(+1.223 \mathrm{e})$ (Table 3) and, in a first approach, can be related with the stabilizing electrostatic interaction between the porphyrin and the fullerene guest. However, as discussed here following, additional contributions to the binding energy provoke a nonlinear correlation between the net charge of the porphyrin central atom and the total association energy.
Table 3. Binding energies, metal-ethylene distances, and natural population analysis (NPA) charges of the porphyrin central atom $(\mathrm{M}=2 \mathrm{H}, \mathrm{Co}, \mathrm{Ni}, \mathrm{Cu}$, $\mathrm{Zn}$ ) calculated at the PBE0-D3/cc-pVTZ level of theory for the simplified porphyrin-ethylene associates.

\begin{tabular}{cccc}
\hline Complex & $\begin{array}{c}E_{\text {bind }} \\
(\mathrm{kcal} / \mathrm{mol})\end{array}$ & $\begin{array}{c}\text { M-ethylene } \\
\text { distance }(\AA)\end{array}$ & $\begin{array}{c}\text { M net } \\
\text { charge }\end{array}$ \\
\hline $\mathbf{2 H P} \cdot \mathbf{C}_{2} \mathrm{H}_{4}$ & -4.636 & 2.986 & +0.942 \\
$\mathbf{C o P} \cdot \mathbf{C}_{2} \mathrm{H}_{4}$ & -8.534 & 2.619 & +0.720 \\
$\mathbf{N i P} \cdot \mathbf{C}_{2} \mathrm{H}_{4}$ & -4.530 & 3.177 & +0.733 \\
$\mathbf{C u P} \cdot \mathbf{C}_{2} \mathrm{H}_{4}$ & -5.965 & 2.997 & +1.006 \\
$\mathbf{Z n P} \cdot \mathbf{C}_{2} \mathrm{H}_{4}$ & -8.047 & 2.749 & +1.223 \\
\hline
\end{tabular}

Symmetry-adapted perturbation theory (SAPT) ${ }^{[24]}$ calculations were performed for $\mathbf{2} \mathrm{HP} \cdot \mathbf{C}_{2} \mathrm{H}_{4}, \mathbf{N i P} \cdot \mathbf{C}_{2} \mathrm{H}_{4}$, and $\mathbf{Z n P} \cdot \mathbf{C}_{2} \mathrm{H}_{4}$ to decompose the total binding energy into electrostatic, exchange, induction, and dispersion energy components (Table 4). SAPT decomposition was not performed for $\mathrm{CoP} \cdot \mathrm{C}_{2} \mathrm{H}_{4}$ and $\mathbf{C u P} \cdot \mathbf{C}_{2} \mathrm{H}_{4}$ because it is not available for open-shell systems. A stabilization in the electrostatic term of more than $10 \mathrm{kcal} / \mathrm{mol}$ is predicted in passing from $\mathbf{N i P} \cdot \mathrm{C}_{2} \mathrm{H}_{4}$ to $\mathbf{Z n P} \cdot \mathbf{C}_{2} \mathrm{H}_{4}$ because of the shorter $\mathrm{M}$ ethylene distance and the larger positive charge held by the metal

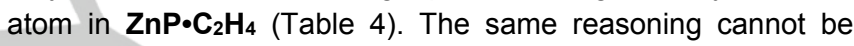
applied to $2 \mathrm{HP} \cdot \mathbf{C}_{2} \mathrm{H}_{4}$, for which the large positive charge accumulated in the $\mathrm{H}$ atoms is not translated into a high electrostatic stabilization due to the comparatively small size of the $\mathrm{H}$ atoms. The exchange interaction contributes positively to the final association energy and is computed to be much larger for $\mathbf{Z n P} \cdot \mathbf{C}_{2} \mathrm{H}_{4}$ than for $\mathbf{2} \mathbf{H P} \cdot \mathbf{C}_{2} \mathrm{H}_{4}$ and $\mathbf{N i P} \cdot \mathbf{C}_{2} \mathrm{H}_{4}$ (Table 4). The shorter metal-ethylene distance and especially the larger atomic size of $\mathrm{Zn}$ magnify the value of this repulsive interaction. The induction term is meant to decrease exponentially with the distance between the two interacting moieties. In $\mathbf{Z n P} \cdot \mathbf{C}_{2} \mathbf{H}_{4}$, for which the M-ethylene distance is significantly small and the $\mathrm{Zn}$ atom bears a relatively large positive charge of $+1.22 \mathrm{e}$, the induction term is computed to be non-negligible $(-4 \mathrm{kcal} / \mathrm{mol})$. For the other two systems, this stabilizing term is less than $1 \mathrm{kcal} / \mathrm{mol}$.

Finally, the dispersion energy is computed to be the largest stabilizing contribution in $\mathbf{2} \mathrm{HP} \cdot \mathbf{C}_{2} \mathrm{H}_{4}$ and $\mathbf{N i P} \cdot \mathbf{C}_{2} \mathrm{H}_{4}$, and it stabilizes the $\mathbf{Z n P} \cdot \mathbf{C}_{2} \mathrm{H}_{4}$ complex in more than $10 \mathrm{kcal} / \mathrm{mol}$ (Table 4). Absolute binding energies at the SAPTO level $\left(2 \mathrm{HP} \cdot \mathbf{C}_{2} \mathrm{H}_{4}\right.$ : $3.472 \mathrm{kcal} / \mathrm{mol}, \mathbf{N i P} \cdot \mathrm{C}_{2} \mathrm{H}_{4}$ : $-4.455 \mathrm{kcal} / \mathrm{mol}, \mathbf{Z n P} \cdot \mathrm{C}_{2} \mathrm{H}_{4}:-8.532$ $\mathrm{kcal} / \mathrm{mol}$ ) nicely match the values obtained at the PBE0-D3/ccpVTZ level (Table 3) except for $\mathbf{2} \mathbf{H P} \cdot \mathbf{C}_{2} \mathbf{H}_{4}$, which is now computed to be slightly less stable than $\mathbf{N i P} \cdot \mathbf{C}_{2} \mathrm{H}_{4}$ in better accord with the experimental evidences. Theoretical calculations therefore suggest that the energy term that mainly contributes to the stabilization of the $\mathbf{2} \mathbf{H P} \cdot \mathbf{C}_{2} \mathbf{H}_{4}$ associate is the dispersion component. In the metal-based porphyrin complexes, the electrostatic contribution acquires a major role, especially for $\mathrm{ZnP} \cdot \mathrm{C}_{2} \mathrm{H}_{4}$, for which $\mathrm{M}$-ethylene distances are shorter and the metal bears a larger positive charge. 
Table 4. Energy decomposition (in $\mathrm{kcal} / \mathrm{mol}$ ) calculated at the SAPT0/def2TZVP level for closed-shell porphyrin-ethylene systems with $\mathrm{M}=2 \mathrm{H}, \mathrm{Ni}, \mathrm{Zn}$.

\begin{tabular}{|c|c|c|c|}
\hline & $2 \mathrm{HP} \cdot \mathrm{C}_{2} \mathrm{H}_{4}$ & $\mathrm{NiP} \cdot \mathrm{C}_{2} \mathrm{H}_{4}$ & $\mathrm{ZnP} \cdot \mathrm{C}_{2} \mathrm{H}_{4}$ \\
\hline Electrostatic & -2.794 & -5.277 & -16.212 \\
\hline Exchange & 7.046 & 8.605 & 22.101 \\
\hline Induction & -0.690 & -0.728 & -3.900 \\
\hline Dispersion & -7.033 & -7.055 & -10.521 \\
\hline TOTAL ${ }^{[a]}$ & -3.472 & -4.455 & -8.532 \\
\hline
\end{tabular}

[a] Total SAPTO energy is corrected according to the spin-component scaling approach.

In conclusion, a new series of supramolecular cup-and-ball complexes has been prepared to evaluate the impact of the metal moiety in the porphyrin fullerene interaction. The high binding constants obtained for [1-M•3] and the large EM of [1-Zn・3] (3.16 $\mathrm{M})$ evidence the nice complementarity of $\pi-\pi$ and ammonium-crown-ether interactions in the self-assembly of the dyads. Further electrochemical and computational studies were also performed. The combination of the experimental and in silico results clearly show that whereas $\pi-\pi$ interactions are governed by dispersion forces in free base porphyrins, they arise both from electrostatic and dispersion interactions in metalloporphyrins.
P. M. Deyà, A. Frontera, R. M. Gomila, C. A. Hunter, J. Am. Chem. Soc. 2006, $128,5560-5569$

[16] D. Bonifazi, G. Accorsi, N. Armaroli, F. Song, A. Palkar, L. Echegoyen, M. Scholl, P. Seiler, B. Jaun, F. Diederich, Helv. Chim. Acta 2005, 88, 1839-1884. [17] M. Nappa, J. S. Valentine, J. Am. Chem. Soc. 1978, 100, 5075-5080.

[18] K. A. Connors, Binding Constants: The Measurement of Molecular Complex Stability, Wiley, 1987.

[19] H. J. Hogben, J. K. Sprafke, M. Hoffmann, M. Pawlicki, H. L. Anderson, J. Am. Chem. Soc. 2011, 133, 20962-20969.

[20] N. Solladié, M. E. Walther, H. Herschbach, E. Leize, A. V. Dorsselaer, T. M. F. Duarte, J.-F. Nierengarten, Tetrahedron 2006, 62, 1979-1987.

[21] M. L'Her, A. Pondaven, in The Porphyrin Handbook (Eds.: K. M. Kadish, K M. Smith, R. Guilard), Academic Press, Amsterdam, 2003, pp. 117-169.

[22] D. V. Konarev, S. S. Khasanov, G. Saito, R. N. Lyubovskaya, J. Porphyrins Phthalocyanines 2003, 07, 801-806.

[23] M. Nishio, M. Hirota, Y. Umezawa, The $\mathrm{CH} / \pi$ Interaction: Evidence, Nature, and Consequences, Wiley, 1998.

[24] E. G. Hohenstein, R. M. Parrish, C. D. Sherrill, J. M. Turney, H. F. Schaefer, J. Chem. Phys. 2011, 135, 174107.

Keywords: Fullerenes • Supramolecular Chemistry • Porphyrin • Crown compounds $\cdot$ Molecular modeling

[1] V. Balzani, A. Credi, M. Venturi, in Molecular Devices and Machines, WileyVCH Verlag GmbH \& Co. KGaA, 2008, pp. 171-207.

[2] a) S. Berardi, S. Drouet, L. Francas, C. Gimbert-Surinach, M. Guttentag, C. Richmond, T. Stoll, A. Llobet, Chem. Soc. Rev. 2014; b) M. D. Kärkäs, E. V. Johnston, O. Verho, B. Åkermark, Acc. Chem. Res. 2013, 47, 100-111.

[3] S. Fukuzumi, in Functional Organic Materials, Wiley-VCH Verlag GmbH \& Co. KGaA, 2007, pp. 465-510.

[4] a) C. Villegas, J. L. Delgado, P.-A. Bouit, B. Grimm, W. Seitz, N. Martin, D. M. Guldi, Chem. Sci. 2011, 2, 1677-1681; b) C. A. Wijesinghe, M. E. El-Khouly, M. E. Zandler, S. Fukuzumi, F. D'Souza, Chem. Eur. J. 2013, 19, 9629-9638; c) H. Imahori, Org. Biomol. Chem. 2004, 2, 1425-1433.

[5] a) N. Martín, J.-F. Nierengarten, Supramolecular Chemistry of Fullerenes and Carbon Nanotubes, Wiley-VCH, Weinheim, 2012; b) M. Kimura, Y. Saito, K. Ohta, K. Hanabusa, H. Shirai, N. Kobayashi, J. Am. Chem. Soc. 2002, 124 5274-5275; c) K. Yoosaf, J. lehl, I. Nierengarten, M. Hmadeh, A.-M. AlbrechtGary, J.-F. Nierengarten, N. Armaroli, Chem. Eur. J. 2014, 20, 223-231; d) F. D'Souza, O. Ito, Chem. Commun. 2009, 4913-4928.

[6] E. M. Pérez, N. Martín, Chem. Soc. Rev. 2008, 37, 1512-1519.

[7] a) M. M. Olmstead, D. A. Costa, K. Maitra, B. C. Noll, S. L. Phillips, P. M. Van Calcar, A. L. Balch, J. Am. Chem. Soc. 1999, 121, 7090-7097; b) P. D. W. Boyd, M. C. Hodgson, C. E. F. Rickard, A. G. Oliver, L. Chaker, P. J. Brothers, R. D. Bolskar, F. S. Tham, C. A. Reed, J. Am. Chem. Soc. 1999, 121, $10487-$ 10495

[8] a) P. D. W. Boyd, C. A. Reed, Acc. Chem. Res. 2004, 38, 235-242; b) G. W. Gokel, L. J. Barbour, R. Ferdani, J. Hu, Acc. Chem. Res. 2002, 35, 878-886.

[9] a) J.-Y. Zheng, K. Tashiro, Y. Hirabayashi, K. Kinbara, K. Saigo, T. Aida, S. Sakamoto, K. Yamaguchi, Angew. Chem. Int. Ed. 2001, 40, 1857-1861; b) K. Tashiro, T. Aida, Chem. Soc. Rev. 2007, 36, 189-197.

[10] D. Sun, F. S. Tham, C. A. Reed, L. Chaker, P. D. W. Boyd, J. Am. Chem. Soc. 2002, 124, 6604-6612.

[11] A. Hosseini, S. Taylor, G. Accorsi, N. Armaroli, C. A. Reed, P. D. W. Boyd, J. Am. Chem. Soc. 2006, 128, 15903-15913.

[12] a) Y.-B. Wang, Z. Lin, J. Am. Chem. Soc. 2003, 125, 6072-6073; b) M.-S.

Liao, J. D. Watts, M.-J. Huang, J. Phys. Chem. B 2007, 111, 4374-4382.

[13] N. Solladié, M. E. Walther, M. Gross, T. M. F. Duarte, C. Bourgogne, J.-F. Nierengarten, Chem. Commun. 2003, 2412-2413.

[14] E. Chekmeneva, C. A. Hunter, M. J. Packer, S. M. Turega, J. Am. Chem. Soc. 2008, 130, 17718-17725.

[15] a) G. Ercolani, L. Schiaffino, in Bioinspiration and Biomimicry in Chemistry, John Wiley \& Sons, Inc., 2012, pp. 47-69; b) P. Ballester, A. I. Oliva, A. Costa, 
Entry for the Table of Contents (Please choose one layout)

Layout 1:

\section{COMMUNICATION}

The pearl in the oyster: The influence of the metal atom in the overall stability of a series of cup and ball complexes formed by a crown porphyrin and a fullerene-ammonium derivative is evaluated. The combination of experimental and in silico studies provides a deep insight into the nature of the porphyrin $\bullet$ fullerene interaction.

Layout 2:

\section{COMMUNICATION}

L. Moreira, J. Calbo, B. M. Illescas, J. Aragó, I. Nierengarten, B. DelavauxNicot, E. Ortí, ${ }^{*}$ N. Martín, * J.-F. Nierengarten*

Page No. - Page No.

Metal-Atom Impact on the SelfAssembly of Cup-and-Ball Metalloporphyrin-Fullerene Conjugates
((Insert TOC Graphic here))

Text for Table of Contents
Author(s), Corresponding Author(s)*

Page No. - Page No.

Title 